\title{
The Association Between The Interval of Radioiodine Treatment and The Response and Adverse Effect in Patients with Non-Progressive Lung Metastases From Differentiated Thyroid Cancer
}

\section{Hongxi Wang}

West China School of Medicine: Sichuan University West China Hospital

\section{Rong Tian ( $\square$ rongtiannuclear@126.com )}

West China School of Medicine: Sichuan University West China Hospital https://orcid.org/0000-00025191-9004

\section{Lei Shi}

Chengdu Fifth People's Hospital

\section{Rui Huang}

West China School of Medicine: Sichuan University West China Hospital

Bin Liu

West China School of Medicine: Sichuan University West China Hospital

\section{Research Article}

Keywords: differentiated thyroid cancer, lung metastases, radioiodine treatment, interval

Posted Date: August 19th, 2021

DOI: https://doi.org/10.21203/rs.3.rs-810367/v1

License: (c) (i) This work is licensed under a Creative Commons Attribution 4.0 International License. Read Full License 


\section{Abstract}

Purpose To assess the association between the interval of radioiodine treatment (RT) and short-term response and adverse effects in patients with non-progressive lung metastases from differentiated thyroid cancer (DTC).

Methods A total of 147 neighboring RT course pairs from 78 patients with ${ }^{131}$ I-avid non-progressive lung metastases from DTC were retrospectively analyzed. The courses were categorized into two groups by interval of neighboring therapeutic 131-I administrations ( $\leq 12$ months and $>12$ months). The short-term therapy response and adverse effects of the two groups were evaluated.

Results No significant differences were found between the two groups in the change rate of thyroid stimulating hormone $(T S H)$ stimulated serum thyroglobulin $(\Delta \mathrm{sTg} \%)(\mathrm{P}=0.806)$ or the change rate of metastasis lesion long diameter $(\triangle L L D \%)(P=0.246)$. In the subanalysis considering the number of treatments ( 3 and $>3$ times), no significant difference was found $(P>0.05)$. No difference was found in biochemical response (interval $\leq 12 \mathrm{~m}: \mathrm{P}=0.325$, interval $>12 \mathrm{~m}: P=0.456$ ) or structural response (interval S12m: $P=0.760$, interval $>12 \mathrm{~m}: \mathrm{P}=0.563$ ) between the former and latter courses with regard to different intervals. No difference was found in adverse events between former and latter courses with regard to different intervals $(P>0.05)$.

Conclusions The interval of RTs is not associated with the short-term response or adverse effects in patients with non-progressive lung metastases from DTC. Appropriately prolonging the interval in specific patients seems to be feasible, and the interval of RT should be individually managed in clinical practice.

\section{Introduction}

Approximately $10 \%$ of patients with differentiated thyroid cancer (DTC) have distant metastases at presentation or during follow-up [1, 2]. The lungs are the most common organ of distant metastases, accounting for $70 \%$ of distant metastasis cases. DTC patients with lung metastases have a relatively poorer prognosis than those without metastases, with a median survival of $<10$ years [3]. In the case of distant metastasis of DTC and continuous iodine uptake at the metastatic lesion, radioiodine $\left({ }^{131} \mathrm{I}\right)$ treatment (RT) is undoubtedly the most effective treatment [4]. However, no consensus is available to identify the treatment interval and influence of the interval of repeated RT on the therapeutic response. A wide selection of treatment intervals ranging from 3 to 12 months has posed challenges to clinicians when developing treatment strategies. The American Thyroid Association (ATA) [5] recommended that micrometastases ( $<2 \mathrm{~mm}$ ) should be treated with repeated RT every 6-12 $\mathrm{m}$ as long as the lesion continues to take up 131-I and respond clinically. For macronodular metastases ( $\geq 2 \mathrm{~mm}$ ), the treatment intervals were suggested to be based on several factors. The benefits and possible adverse effects of repeated RT must be balanced to obtain a good therapeutic effect and improve the quality of life of patients $[6,7]$. 
On the premise of ensuring the therapeutic effect, appropriately extending the interval might decrease the treatment frequency and incidence of adverse effects, with robust compliance of patients. However, reliable evidence about the potential association of longer intervals and outcomes is lacking. Thus, we performed this retrospective course-based study to assess whether the interval between neighboring therapeutic 131-I administrations is associated with short-term response and adverse effects in DTC patients with non-progressive ${ }^{131} \mathrm{l}$-avid lung metastases, aiming at optimizing the management of DTC patients who need repeated RT.

\section{Materials And Methods}

\section{Patients and RT course pairs}

A retrospective analysis of DTC patients with lung metastases treated at the Nuclear Medicine Department of West China Hospital of Sichuan University from January 2009 to August 2018 was performed. The institution is a tertiary-care university teaching hospital in southwestern China and a referral center for thyroid cancer treatment. The study was approved by the local institutional review board, and the requirement for written informed consent was waived. The inclusion criteria were as follows: 1) patients who received total thyroidectomy or near-total thyroidectomy, and neck dissection was performed if any enlarged lymph node suspicious for malignancy was present in the preoperative radiologic examinations; 2 ) patients who were diagnosed with lung metastases demonstrated by initial Rx-WBS; and 3) first 131-I treatment performed within $6 \mathrm{~m}$ post-thyroidectomy. The exclusion criteria were as follows: 1) patients with other distant metastases; 2) patients with a concomitant second primary cancer; and 3) patients who underwent pulmonary lobectomy beyond RTs.

A course pair was constituted by neighboring two RTs (the former course and the latter course). If a patient underwent three courses of RT, the second course acted as not only the latter course of the first course pair but also the former course of the second course pair, and so on [8]. The exclusion criteria of course pairs were as follows: 1 ) a course pair constituted by the first and second RTs; 2) TSH levels after levothyroxine withdrawal of two RTs were comparable and anti-Tg antibody (TgAb) was $>40.0 \mathrm{IU} / \mathrm{ml}[9]$, 3) sTg and CT imaging was available for response evaluation, and 4) a course pair with an interval $>24$ months due to poor compliance of patients.

\section{Protocols of repeated $131-$ I treatment}

All patients withdrew thyroid hormone medication 2-3wks and began a low iodine diet 3-4wks before RT. Repeated RT was performed with a 131-I dose of 3.7-7.4 GBq. The 131-I post therapeutic whole body scan (R-WBS) and/or 131-I single photon emission computed tomography/computed tomography (SPECT/CT) was performed 3-5d after 131-I administration. The RT stops once no 131-I uptake is present on a diagnostic WBS (D-WBS) or R-WBS, or metastases structurally progress despite 131-I uptake [5].

\section{TSH-stimulated Tg measurements}


Thyroid stimulating hormone (TSH)-stimulated (sTg) and anti-Tg autoantibody (TgAb) levels were measured with the same high-sensitivity electrochemiluminescence immunoassay after thyroid hormone withdrawal and just before the 131-I administration in the same laboratory. The assay used was the Roche Elecsys 2010 system (Roche Diagnostics GmbH, Mannheim, Germany) which was calibrated against the CRM-457 standard, with a sensitivity of $0.04 \mathrm{ng} / \mathrm{mL}$ and a reference range of $0.5-55 \mathrm{ng} / \mathrm{mL}$. Quality control was ensured by assaying two levels of control sera in each series and by reassessing all sera showing a coefficient of variation exceeding $10 \%$.

\section{Computed tomography scan protocol}

A chest computed tomography (CT) scan without iodinated contrast was performed extending from the lung apex to the adrenal glands at full inspiration just before 131-I administration. Patients underwent scanning with a multi-detector CT scanner (Somatom Definition Flash, Siemens Healthcare) with the following parameters: tube voltage, $100 \mathrm{kVp}$; tube current, $100 \mathrm{mAs}$; thickness, $1.00 \mathrm{~mm}$; interval, 1.00 mm; pitch, 1.2.

\section{Serologic and structural response evaluation}

The comparison between the change rate of the sTg level $(\Delta \mathrm{sTg} \%)$ and the change rate of LLD ( $\Delta \mathrm{LLD} \%)$ of the two groups with different intervals was performed. $\Delta \mathrm{sTg} \%$ was defined as follows: $\Delta \mathrm{sTg} \%=[\mathrm{sTg}$ (the latter course) - sTg (the former course)]/sTg (the former course) $\times 100 \% . \Delta \mathrm{LLD} \%$ was defined as follows: $\Delta L L D \%=$ [LLD (the latter course)- LLD (the former course)] /LLD (the former course) $\times 100 \%$.

The $\Delta \mathrm{sTg} \%$ results were further classified as serologic effectiveness and serologic non-effectiveness [10, 11]. Serologic effectiveness was defined as a reduction in the $\mathrm{Tg}$ level by at least $25 \%(\Delta \mathrm{sTg} \% \leq-25 \%)$. For serologic non-effectiveness, the Tg level decreased by less than $25 \%$ or increased $(\Delta s \mathrm{Tg} \%>-25 \%)$. The $\triangle \mathrm{LLD} \%$ results were classified as structural complete remission (CR), structural partial remission (PR), structural stable disease (SD), and structural progressive disease (PD) according to the RECIST 1.1-like criteria (Supplemental Data) $[12,13]$. The comparasion of responses between former and latter courses with regard to different intervals was performed.

\section{Adverse effect evaluation}

The incidences of adverse effects were evaluated. The following indices were included: leukocytes, platelets, aspartate aminotransferase (AST), alanine aminotransferase (ALT), calcium (Ca), and salivary gland imaging. Leukocytes, platelets, AST, ALT, and Ca were measured after thyroid hormone withdrawal and just before the 131-I administration in the same laboratory. The adverse effects were then graded and evaluated according to National Cancer Institute Common Toxicity Criteria (NCl-CTC) version 2.0. The Grade 0 was recorded as normal, and grades $1-4$ were recorded as abnormal. The salivary gland imaging scan protocol was shown in Supplemental Data. Salivary gland function was visually evaluated as normal or abnormal, by a nuclear medicine physician.

\section{Statistical analysis}


Continuous variables are expressed as the means \pm standard deviations (SDs) or the medians (p25 to p75), and categorical variables are presented as numbers. The Chi-square test or Fisher's exact test and $t$ test or Wilcoxon test were performed to compare the distributions of categorical and continuous variables, respectively. To evaluate the differences in response and adverse effects between the two groups with different intervals, the stratified Cochran-Mantel-Haenszel test was used. A p value $<0.05$ was considered statistically significant. All statistical analyses were performed using IBM SPSS Statistics software (version 25.0; IBM Corporation, Armonk, NY, USA).

\section{Results}

\section{Characteristics of patients and courses}

A total of 234 patients with lung metastases were consecutively enrolled from May 1st, 2008 through December 31st, 2020. After the exclusion of patients and course pairs, 147 course pairs of 78 patients were finally established and utilized. The flowchart of inclusion and exclusion is shown in Fig. 1. Course pairs were then categorized into two groups based on the interval between neighboring two RTs: 1$) \leq 12$ $m(n=81)$, and 3$)>12 m(n=66)$.

The characteristics of 78 patients are shown in Table 1. The mean age at metastatic DTC diagnosis was $35.14 \pm 15.88$ years. Sixty-one (74.4\%) patients were female, and 21 (25.6\%) were male. At the time of the data lock (June, 2021), two patients were considered to have an excellent response to treatment (a suppressed $\mathrm{Tg}<1 \mathrm{ng} / \mathrm{mL}$ and no structural evidence of disease) after undergoing 6 and 5 times RTs. Two patients had no structural evidence of disease after undergoing 5 and 8 times RTs. The RT was stopped in 7, 11, and 12 patients due to no I-131 uptake present on R-WBS, metastasis progression despite I-131 uptake, and personal reasons, respectively. Therefore, 30 (38.5\%) patients underwent three times of RTs, and $48(61.5 \%)$ underwent four or more times of RTs. 
Table 1

Characteristics of 147 former courses from 78 patients.

\begin{tabular}{|c|c|c|c|c|}
\hline \multirow[t]{3}{*}{ Characteristics } & \multirow{3}{*}{$\begin{array}{l}78 \\
\text { patients }\end{array}$} & \multicolumn{3}{|c|}{147 former courses } \\
\hline & & $\begin{array}{l}\text { Interval } \leq \\
12 \mathrm{~m}\end{array}$ & $\begin{array}{l}\text { Interval > } 12 \mathrm{~m}(\mathrm{n} \\
=66)\end{array}$ & $\begin{array}{l}\mathrm{P} \\
\text { value }\end{array}$ \\
\hline & & \multicolumn{3}{|l|}{$(n=81)$} \\
\hline $\begin{array}{l}\text { Age at metastases diagnosis (years), } \\
\text { mean } \pm \text { SD }\end{array}$ & $\begin{array}{l}35.14 \pm \\
15.88\end{array}$ & $\begin{array}{l}34.09 \pm \\
15.25\end{array}$ & $32.69 \pm 15.77$ & 0.512 \\
\hline \multicolumn{5}{|l|}{ Gender, n (\%) } \\
\hline Male & $21(25.6)$ & $20(24.7)$ & $41(62.1)$ & 0.319 \\
\hline Female & $61(74.4)$ & $61(75.3)$ & $25(37.9)$ & \\
\hline \multicolumn{5}{|l|}{ Histology, n (\%) } \\
\hline Papillary & $63(80.8)$ & $74(91.4)$ & $59(89.4)$ & 0.748 \\
\hline Follicular variant of papillary & $13(16.7)$ & $3(3.7)$ & $6(9)$ & \\
\hline Follicular & $4(2.5)$ & $4(4.9)$ & $1(1.6)$ & \\
\hline T stage, $\mathrm{n}(\%)$ & & & & 0.755 \\
\hline $\mathrm{T} 1 \mathrm{~b}$ & $4(2.6)$ & $4(4.9)$ & $4(6.0)$ & \\
\hline $\mathrm{T} 2$ & $3(3.8)$ & $3(3.7)$ & $3(4.7)$ & \\
\hline ТЗа & $5(6.4)$ & $4(4.9)$ & $5(7.6)$ & \\
\hline T3b & $8(10.3)$ & $2(2.5)$ & $7(10.6)$ & \\
\hline $\mathrm{T} 4 \mathrm{a}$ & $22(28.2)$ & $21(26.0)$ & $20(30.3)$ & \\
\hline $\mathrm{T} 4 \mathrm{~b}$ & $3(3.7)$ & $3(3.7)$ & $4(6.0)$ & \\
\hline Tx & $30(38.5)$ & $44(54.3)$ & $23(34.8)$ & \\
\hline $\mathrm{N}$ stage, $\mathrm{n}(\%)$ & & & & 0.888 \\
\hline NO & $4(6.4)$ & $2(2.5)$ & $3(4.7)$ & \\
\hline N1 & $62(79.5)$ & $63(77.8)$ & $56(84.7)$ & \\
\hline Nx & $11(14.1)$ & $16(19.7)$ & $7(10.6)$ & \\
\hline ENE, n (\%) & & & & 0.319 \\
\hline Yes & $14(17.9)$ & $42(51.9)$ & $31(47.0)$ & \\
\hline No & $40(51.3)$ & $12(14.7)$ & $14(21.2)$ & \\
\hline
\end{tabular}




\begin{tabular}{|c|c|c|c|c|}
\hline \multirow[t]{3}{*}{ Characteristics } & \multirow{3}{*}{$\begin{array}{l}78 \\
\text { patients }\end{array}$} & \multicolumn{3}{|c|}{147 former courses } \\
\hline & & $\begin{array}{l}\text { Interval } \leq \\
12 \mathrm{~m}\end{array}$ & $\begin{array}{l}\text { Interval > } 12 \mathrm{~m} \text { (n } \\
=66)\end{array}$ & $\begin{array}{l}P \\
\text { value }\end{array}$ \\
\hline & & \multicolumn{3}{|l|}{$(n=81)$} \\
\hline Missing & $24(30.8)$ & $27(33.4)$ & $21(31.8)$ & \\
\hline Lesion size, $\mathrm{n}(\%)$ & & & & 0.206 \\
\hline$<1 \mathrm{~cm}$ & $72(93.6)$ & $74(91.4)$ & $63(95.3)$ & \\
\hline$\geq 1 \mathrm{~cm}$ & $6(6.4)$ & $7(8.6)$ & $3(4.7)$ & \\
\hline Number of treatments, n (\%) & & & & 0.510 \\
\hline 3 & $30(38.5)$ & $30(37.0)$ & $21(31.8)$ & \\
\hline$\geq 3$ & $48(61.5)$ & $51(63.0)$ & $45(68.2)$ & \\
\hline Cumulative dose (GBq), n (\%) & & & & 0.623 \\
\hline$<22.2$ & $13(16.7)$ & $11(13.6)$ & $0(0.0)$ & \\
\hline$\geq 22.2$ & 65 (83.3) & $70(86.4)$ & $66(100.0)$ & \\
\hline
\end{tabular}

Additionally, the characteristics of 147 former courses from 77 patients, grouped by interval, are shown in Table 1. Fifty-one (34.7\%) former courses were second RTs, and 96 (65.3\%) former courses were third or more RTs. Interval was ranged from 126 to 937 days. The median values of the interval in treatment times of former courses (second, third and more RTs) were 358 and 357 days, respectively. The median (P25, P75) interval was 287 days $(211,346)$ and 513 days $(399,710)$ in the two groups. We retrospectively analyzed how the interval of courses was decided clinically if the interval was $>12 \mathrm{~m}(\mathrm{n}=$ 66), and the interval was prolonged in $47(71.2 \%)$ and 17 (25.8\%) courses due to patient personal reasons and physician advice, respectively. The decision method of the interval of $2(3 \%)$ courses was unclear. No significant differences in characteristics were found between the two groups.

\section{The $\Delta s T g \%$ and the $\Delta L L D \%$ of courses}

Regarding the sTg levels of the 147 former courses, in the group with an interval of $\leq 12 \mathrm{~m}$, the sTg levels just before RTs were $101.1(29.0,5000.0) \mathrm{ng} / \mathrm{ml}$ with a median TSH of $83.8(51.4,100.0) \mathrm{mIU} / \mathrm{L}$. At the latter courses, the median sTg declined to $87.64(23.83,321.4) \mathrm{ng} / \mathrm{ml}$ with a median TSH of 88.0 (54.0, $100.0) \mathrm{mIU} / \mathrm{L}$, yielding a median $\Delta \mathrm{sTg} \%$ of $-29.0 \%(-44.2,-12.7)$. In the group with an interval of $>12 \mathrm{~m}$, the sTg levels just before RTs were $134.0(29.3,592.9) \mathrm{ng} / \mathrm{ml}$ with a median TSH of $85.2(47.1,100.0)$ $\mathrm{mIU} / \mathrm{L}$. The median sTg declined to $95.5(32.8,247.0) \mathrm{ng} / \mathrm{ml}$ with a median TSH of $78.4(55.6,100.0)$ $\mathrm{mIU} / \mathrm{L}$ at the latter courses, yielding a median $\Delta \mathrm{sTg} \%$ of $-34.0 \%(-56.3 \%,-7.6 \%)$. We compared $\Delta \mathrm{s} T g \%$ of 
the two groups in all pairs and in a subanalysis of number of treatments (latter course was third RTs, and fourth and more RTs). The median $\Delta \mathrm{sTg} \%$ of the two groups was $-35.0 \%(-51.6 \%,-11.2 \%)$ and $-31.0 \%$ $(-56.5 \%,-12.6 \%)$ if the latter course was third RT. The median $\Delta \mathrm{sTg} \%$ of the two groups was $-25.0 \%$ $(-37.3 \%,-14.2 \%)$ and $-34.0 \%(-55.8 \%,-6.6 \%)$ if the latter course was fourth and more RT. No significant differences in $\Delta s T g \%$ were found between the two groups in any pairs $(P=0.806)$ or in a subanalysis of number of treatments $(P=0.825, P=0.548)$ (Table 2).

Table 2

The $\Delta s T g \%$ and the $\Delta L L D \%$ of latter courses.

\begin{tabular}{|llll|}
\hline Median (p25, p75) & \multicolumn{1}{l}{ Interval } & \\
\cline { 2 - 4 } & $\mathbf{5 1 2} \mathbf{~}(\mathbf{n}=\mathbf{8 1})$ & $\mathbf{> 1 2} \mathbf{~} \mathbf{( n = 6 6 )}$ & P value \\
\hline Treatment times $=3$ & & & \\
\hline$\Delta$ sTg\% & $-35.0(-51.6,-11.2)$ & $-31.0(-56.5,-12.6)$ & 0.825 \\
\hline$\Delta$ LLD\% & $0(0,0)$ & $0(0,0)$ & 0.240 \\
\hline Treatment times $>3$ & & & \\
\hline$\Delta$ sTg\% & $-25.0(-37.3,-14.2)$ & $-34.0(-55.8,-6.6)$ & 0.548 \\
\hline$\Delta$ LLD\% & $0(0,0)$ & $0(0,0)$ & 0.267 \\
\hline Total & & & \\
\hline$\Delta s T g \%$ & $-29.0(-44.2,-12.7)$ & $-34.0(-56.3,-7.6)$ & 0.806 \\
\hline$\Delta$ LLD\% & $0(0,0)$ & $0(0,0)$ & 0.246 \\
\hline
\end{tabular}

Regarding the LLD value of the 147 former courses, in the group with interval of $\leq 12 \mathrm{~m}$, the median LLD value just before RTs and at the latter courses were both $3 \mathrm{~mm}(2 \mathrm{~mm}, 5 \mathrm{~mm})$, yielding a median $\triangle L L D \%$ of $0.0 \%$. In the group with an interval of $\leq 12 \mathrm{~m}$, the median LLD value just before RTs and at the latter courses both was $2 \mathrm{~mm}(2 \mathrm{~mm}, 4 \mathrm{~mm})$, with a median $\triangle L L D \%$ of $0.0 \%$. No significant differences in $\triangle L L D \%$ were found between the two groups in any pairs $(P=0.246)$ or in a subanalysis of number of treatments $(P=0.240, P=0.267)$ (Table 2$)$.

\section{The response evaluation of courses}

The flow of patients in course pairs according to biochemical and structural response is shown in Fig. 2 . No difference was found in biochemical response between former and latter courses with regard to different interval (interval $\leq 12 \mathrm{~m}: \mathrm{P}=0.325$, interval $>12 \mathrm{~m}: \mathrm{P}=0.456$ ). No difference was found in structural response between former and latter courses with regard to different interval (interval $\leq 12 \mathrm{~m}: \mathrm{P}$ 
$=0.760$, interval $>12 \mathrm{~m}: \mathrm{P}=0.563)$. Representative patient who responded to repeated RTs and then underwent the next RT with an interval of $>12 \mathrm{~m}$ was illustrated in Fig. 3.

\section{The adverse effect evaluation of courses}

The adverse effects of the 147 Courses are shown in Table 3. No difference was found in adverse events between former and latter courses with regard to different intervals $(P>0.05)$. 
Table 3

The adverse effect evaluation of 147 courses.

\begin{tabular}{|c|c|c|c|c|}
\hline \multirow{2}{*}{\multicolumn{2}{|c|}{ Former courses }} & \multicolumn{3}{|c|}{ Latter courses, n (\%) } \\
\hline & & Normal & Abnormal & $P$ value* \\
\hline \multicolumn{4}{|c|}{ Salivary gland function } & 0.154 \\
\hline \multirow[t]{2}{*}{$\leq 12 \mathrm{~m}$} & Normal & 39 & 37 & \\
\hline & Abnormal & 46 & 44 & \\
\hline \multirow[t]{2}{*}{$>12 \mathrm{~m}$} & Normal & 26 & 23 & \\
\hline & Abnormal & 40 & 43 & \\
\hline \multicolumn{2}{|c|}{ Leukocytes } & & & 0.187 \\
\hline \multirow[t]{2}{*}{$\leq 12 \mathrm{~m}$} & Normal & 64 & 39 & \\
\hline & Abnormal & 17 & 42 & \\
\hline \multirow[t]{2}{*}{$>12 \mathrm{~m}$} & Normal & 25 & 63 & \\
\hline & Abnormal & 0 & 3 & \\
\hline \multicolumn{2}{|l|}{ Platelets } & & & 0.467 \\
\hline \multirow[t]{2}{*}{$\leq 12 \mathrm{~m}$} & Normal & 59 & 51 & \\
\hline & Abnormal & 22 & 30 & \\
\hline \multirow[t]{2}{*}{$>12 \mathrm{~m}$} & Normal & 65 & 65 & \\
\hline & Abnormal & 1 & 1 & \\
\hline \multicolumn{2}{|l|}{ AST } & & & 0.761 \\
\hline \multirow[t]{2}{*}{$\leq 12 \mathrm{~m}$} & Normal & 65 & 67 & \\
\hline & Abnormal & 16 & 14 & \\
\hline \multirow[t]{2}{*}{$>12 \mathrm{~m}$} & Normal & 66 & 62 & \\
\hline & Abnormal & 0 & 4 & \\
\hline \multicolumn{2}{|l|}{ ALT } & & & 0.986 \\
\hline \multirow[t]{2}{*}{$\leq 12 \mathrm{~m}$} & Normal & 71 & 70 & \\
\hline & Abnormal & 10 & 11 & \\
\hline \multirow[t]{2}{*}{$>12 \mathrm{~m}$} & Normal & 65 & 61 & \\
\hline & Abnormal & 1 & 5 & \\
\hline
\end{tabular}




\begin{tabular}{|lllll|}
\hline Former courses & \multicolumn{2}{l|}{ Latter courses, $\mathbf{n}(\%)$} \\
\cline { 3 - 5 } & Normal & Abnormal & P value* \\
\hline Calcium & & & 0.072 \\
\hline$\leq 12 \mathrm{~m}$ & Normal & 27 & 16 & \\
\hline$>12 \mathrm{~m}$ & Abnormal & 54 & 65 & \\
\hline & Normal & 54 & 53 & \\
\hline AST, aspartate aminotransferase. ALT, alanine aminotransferase. ${ }^{*}$ Cochran-Mantel-Haenszel test. \\
\hline
\end{tabular}

\section{Discussion}

Repeated RT has been widely implemented in treating of DTC with lung metastasis if the lesion continues to take up 131-I and respond clinically. However, in patients with structural non-progressive lung metastases from DTC, especially after cumulative activities of $22.2 \mathrm{GBq}$. We may face one question: for patients who need to receive multiple RTs, what is the optimal timepoint for next RT considering of a balance of benefit and adverse effects? We performed this retrospective study to evaluate the association between the interval of RTs and short-term response and adverse effects in patients who underwent multiple RTs. We found that the interval of multiple RTs did not affect short-term biochemical response, structural response or adverse effects.

The ATA guideline [5] suggested that an interval that is too short $(<6 \mathrm{~m})$ should be avoided because it frequently interrupts thyroid-stimulating hormone (TSH) inhibition therapy, which may stimulate follicular cells and increase the risk of tumor recurrence. Additionally, patients may receive more frequent RTs and more quickly achieve cumulative activity of $22 \mathrm{GBq}$ if the interval is short. It is confirmed that RT efficacy is mainly associated with the expression of NIS in patients who had been treated with a cumulative activity of $22 \mathrm{GBq}$, and the impairment of iodine uptake may cause delayed curative effects or disease progression $[4,14]$. One study reported that $C R$ was more likely to be achieved when the metastatic lesion dose was $>80-100 \mathrm{~Gy}$, but it was rare for dosimetry to show a dose $>20$ Gy after cumulative activities of $20 \mathrm{GBq}[15]$.

On the flip side, longer interval may decrease the number of stimulating follicular cells, reduce the frequency of multiple RTs, more slowly achieve a cumulative activity of $22 \mathrm{GBq}$, and minimize the risk of late effects of 131-I in patients who had been treated with a cumulative activity of $22 \mathrm{GBq}$. In this retrospective study, courses were categorized into two groups by interval ( $\leq 12 \mathrm{~m},>12 \mathrm{~m}$ ). Although a decline in sTg was observed in the two groups, no significant differences were found between the two groups in $\Delta s T g \%$ and $\Delta L L D \%$, and no difference was found in biochemical or structural response between the former and latter courses with regard to different intervals. Additionally, we further performed a subanalysis of number of treatments ( 3 times, $>3$ times), considering that patients usually achieve a 
cumulative activity of $22 \mathrm{GBq}$ after undergoing three RTs. No significant differences were found in the subanalysis. These results present primary evidence for the assumption above.

On the other hand, a low risk of early- and late-onset complications (salivary gland damage, dental caries, nasolacrimal duct obstruction, and secondary malignancies) is associated with the cumulative administered activity of $131-I$ and the total number of treatments [16-18]. We evaluated whether prolonging intervals prevent several early adverse effects, and no difference was found in salivary gland function, leukocytes, platelets, AST, ALT, and Ca between former and latter courses with regard to different intervals. With a consideration of a short-term observation window, the effect of interval on late-onset complications needs to be evaluated in the future.

Two issues urgently need to be discussed in this situation. First, how can candidates who may benefit from longer intervals be identified in clinical practice? In this cohort, if lung metastases were ${ }^{131}$ l-avid, lesions were structurally stable or permissive and adverse effects were acceptable, patients would have an indication to receive repeated 131-I administrations. We did not exclude the former course of which patients were evaluated as serologic stabilization and non-effectiveness, because waiting at least 12 months for serologic progression would better establish a trend to ensure that the rise in the $\mathrm{Tg}$ or $\mathrm{TgAb}$ levels is not spurious or due to ${ }^{131}$-induced tumor destruction [16]. Due to the limitation of the retrospective design, we did not identify a potential index for prolonging the interval. Second, what is the reasonable maximal length of time interval? The ATA recommended that the upper limitation value of the interval was $12 \mathrm{~m}$ for micrometastases, which is unclear for macronodular metastases. In this cohort, the median value of interval was 513 days (ranging from 126 to 937 days) in groups with >12 m intervals, and number of treatments were not associated with intervals. This prolonged interval may not be enough to identify the maximal length of the time interval for multiple RTs.

Indeed, the interval of treatment for each patient should be individually managed in clinical practice, and several factors should be considered as well, such as age, the therapeutic response, cumulative dose, risk of complications, additional treatments, and patient desires $[4,5,19]$, which need to be confirmed in prospective studies. As the 65-year-old male presented in Fig. 3, he had undergone three RTs with a cumulative dose of $600 \mathrm{mCi}$. Considering the good response, older age, and risk of pulmonary fibrosis, we prolonged the interval with close follow-up. After a longer interval (937 days), the patients still achieved remarkable serologic and structural responses. At the last follow-up (2 months after the fourth RT), the TSH-suppressed Tg showed a continuous decline.

Our study had some limitations. First, the small number of patients might cause an insufficient statistical power. Second, there may be a potential bias of patient selection (young patients, mostly PTC, lesion $<1$ $\mathrm{cm}$ ), because we focused on patients with non-progressive lung metastases, and older age, FTC, and lesion size of $\geq 1 \mathrm{~cm}$ were associated with disease progression. Therefore, the generalizability of the results needs to be confirmed. Third, the effect of extending the interval time of RTs on the long-term outcomes and adverse effects of patients is unclear. 


\section{Conclusion}

The interval of RT is not associated with the short-term response and adverse effects in patients with non-progressive lung metastases from DTC. Appropriately prolonging the interval in specific patients seems to be feasible, until further data are available. The interval for each patient should be individually managed in clinical practice, balancing the therapeutic response, cumulative dose, risk of complications, additional treatments and patient desires.

\section{Declarations}

Conflict of interest: The authors declare that they have no conflict of interest.

Informed consent: The study was approved by the Institutional Review Board of West China Hospital, Sichuan University and the requirement of written informed consent was waived.

Ethical approval: All procedures performed in studies involving human participants were in accordance with the ethical standards of the institutional research committee and with the 1964 Helsinki declaration and its later amendments or comparable ethical standards.

Financial disclosure: This study has received funding by the Science and Technology Department of Sichuan Province (19ZDYF1737).

\section{References}

1. S.Y. Sohn, H.I. Kim, Y.N. Kim, T.H. Kim, S.W. Kim, J.H. Chung, Prognostic indicators of outcomes in patients with lung metastases from differentiated thyroid carcinoma during long-term follow-up. Clin Endocrinol. 88, 318-326 (2018)

2. M.C. Kreissl, M.J.R. Janssen, J. Nagarajah, Current treatment strategies in metastasized differentiated thyroid cancer. J Nucl Med 60, 9-15 (2019)

3. H.J. Song, Z.L. Qiu, C.T. Shen, W.J. Wei, Q.Y. Luo, Pulmonary metastases in differentiated thyroid cancer: Efficacy of radioiodine therapy and prognostic factors. Eur. J. Endocrinol. 173, 399-408 (2015)

4. C. Durante, N. Haddy, E. Baudin, S. Leboulleux, D. Hartl, J.P. Travagli, B. Caillou, M. Ricard, J.D. Lumbroso, F. De Vathaire, M. Schlumberger, Long-term outcome of 444 patients with distant metastases from papillary and follicular thyroid carcinoma: benefits and limits of radioiodine therapy. J Clin Endocrinol Metab. 91, 2892-2899 (2006)

5. B.R. Haugen, E.K. Alexander, K.C. Bible, G.M. Doherty, S.J. Mandel, Y.E. Nikiforov, F. Pacini, G.W. Randolph, A.M. Sawka, M. Schlumberger, K.G. Schuff, S.I. Sherman, J.A. Sosa, D.L. Steward, R.M. Tuttle, L. Wartofsky, 2015 American Thyroid Association Management Guidelines for Adult Patients with Thyroid Nodules and Differentiated Thyroid Cancer: The American Thyroid Association 
Guidelines Task Force on Thyroid Nodules and Differentiated Thyroid Cancer. Thyroid. 26, 1-133 (2016)

6. D. Van Nostrand, The benefits and risks of I-131 therapy in patients with well-differentiated thyroid cancer. Thyroid. 19, 1381-1391 (2009)

7. B.H.H. Lang, K.P. Wong, C.Y. Cheung, K.Y. Wan, C.Y. Lo, Evaluating the prognostic factors associated with cancer-specific survival of differentiated thyroid carcinoma presenting with distant metastasis. Ann Surg Oncol. 20, 1329-1335 (2013)

8. R. Sa, L. Cheng, Y. Jin, H. Fu, Y. Shen, L. Chen, Distinguishing Patients With Distant Metastatic Differentiated Thyroid Cancer Who Biochemically Benefit From Next Radioiodine Treatment. Front Endocrinol (Lausanne). 11, 587315 (2020)

9. C. Alexander, J.B. Bader, A. Schaefer, C. Finke, C.M. Kirsch, Intermediate and long-term side effects of high-dose radioiodine therapy for thyroid carcinoma. J Nucl Med. 39, 1551-1554 (1998)

10. X.Y. Zhang, J.W. Sun, Z.L. Qiu, Y. Wang, X.Y. Chen, J.H. Zhao et al., Clinical outcomes and prognostic factors in patients with no less than three distant organ system metastases from differentiated thyroid carcinoma. Endocrine. 66, 254-265 (2019)

11. S. Wu, H. Wang, Efficacy analysis of (131)I therapy and predictive value of preablation stimulated thyroglobulin for lung metastases from differentiated thyroid cancer. Ann Endocrinol (Paris) 74, $40-$ 44 (2013)

12. E.A. Eisenhauer, P. Therasse, J. Bogaerts, L.H. Schwartz, D. Sargent, R. Ford, J. Dancey, S. Arbuck, S. Gwyther, M. Mooney, L. Rubinstein, L. Shankar, L. Dodd, R. Kaplan, D. Lacombe, J. Verweij, New response evaluation criteria in solid tumours: Revised RECIST guideline (version 1.1). Eur. J. Cancer 45, 228-247 (2013)

13. M.M. Sabra, J.M. Dominguez, R.K. Grewal, S.M. Larson, R.A. Ghossein, R.M. Tuttle, J.A. Fagin, Clinical outcomes and molecular profile of differentiated thyroid cancers with radioiodine-avid distant metastases. J Clin Endocrinol Metab. 98, 829-836 (2013)

14. M. Qutbi, B. Shafeie, M. Amoui, F. Tabeie, Z. Azizmohammadi, A. Mahmoud-Pashazadeh, H. Javadi, M. Assadi, I.N. Asli, Evaluation of Prognostic Factors Associated With Differentiated Thyroid Carcinoma With Pulmonary Metastasis. Clin. Nucl. Med. 41, 917-921 (2016)

15. K. Sugino, M. Nagahama, W. Kitagawa, K. Ohkuwa, T. Uruno, K. Matsuzu, A. Suzuki, C. Tomoda, K.Y. Hames, J. Akaishi, C. Masaki, K. Ito, Distant Metastasis in Pediatric and Adolescent Differentiated Thyroid Cancer: Clinical Outcomes and Risk Factor Analyses. J Clin Endocrinol Metab. 105, dgaa545 (2020)

16. F.A. Verburg, U. Mäder, M. Luster, H. Hänscheid, C. Reiners, Determinants of successful ablation and complete remission after total thyroidectomy and ${ }^{131}$ I therapy of paediatric differentiated thyroid cancer. Eur J Nucl Med Mol Imaging. 42, 1390-1398 (2015)

17. F. Sun, G.E. Gerrard, J.K. Roberts, T. Telford, S. Namini, M. Waller, G. Flux, V.M. Gill, Ten Year Experience of Radioiodine Dosimetry: is it Useful in the Management of Metastatic Differentiated Thyroid Cancer? Clin Oncol (R Coll Radiol). 29, 310-315 (2017) 
18. G.L. Francis, S.G. Waguespack, A.J. Bauer, P. Angelos, S. Benvenga, J.M. Cerutti, C.A. Dinauer, J. Hamilton, I.D. Hay, M. Luster, M.T. Parisi, M. Rachmiel, G.B. Thompson, S. Yamashita, \American Thyroid Association Guidelines Task Force. Management Guidelines for Children with Thyroid Nodules and Differentiated Thyroid Cancer. Thyroid. 25, 716-759 (2015)

19. D. Albano, F. Bertagna, M.B. Panarotto, R. Giubbini, Early and late adverse effects of radioiodine for pediatric differentiated thyroid cancer. Pediatr Blood Cancer. 64 (2017)

20. E. Kalender, Y. Zeki Celen, U. Elboga, H. Deniz Demir, M. Yilmaz, Lung metastases in patients with differentiated thyroid carcinoma and evaluation of response to radioiodine therapy. Rev Esp Med Nucl Imagen Mol 31, 328-331 (2012)

21. A.J.M. Rombouts, N. Hugen, M.A.G. Elferink, I.D. Nagtegaal, J.H.W. de Wilt, Treatment Interval between Neoadjuvant Chemoradiotherapy and Surgery in Rectal Cancer Patients: A PopulationBased Study. Ann Surg Oncol. 23, 3593-3601 (2016)

\section{Figures}




\section{Patients who were diagnosed with lung metastases from DTC}

$(n=234)$

Exclusion criteria for patients:

1. Patients with I-131 non-avid metastases $(n=36)$;

2. Patients with secondary metastases $(n=10)$;

3. Patients who underwent first 131-I treatment $>6 \mathrm{~m}$ after thyroidectomy $(n=9)$;

3. Patients with other distant metastases $(n=25)$;

4. Patients with concomitant other malignance $(n=3)$;

4. Patients received pulmonary lobectomy $(n=2)$.

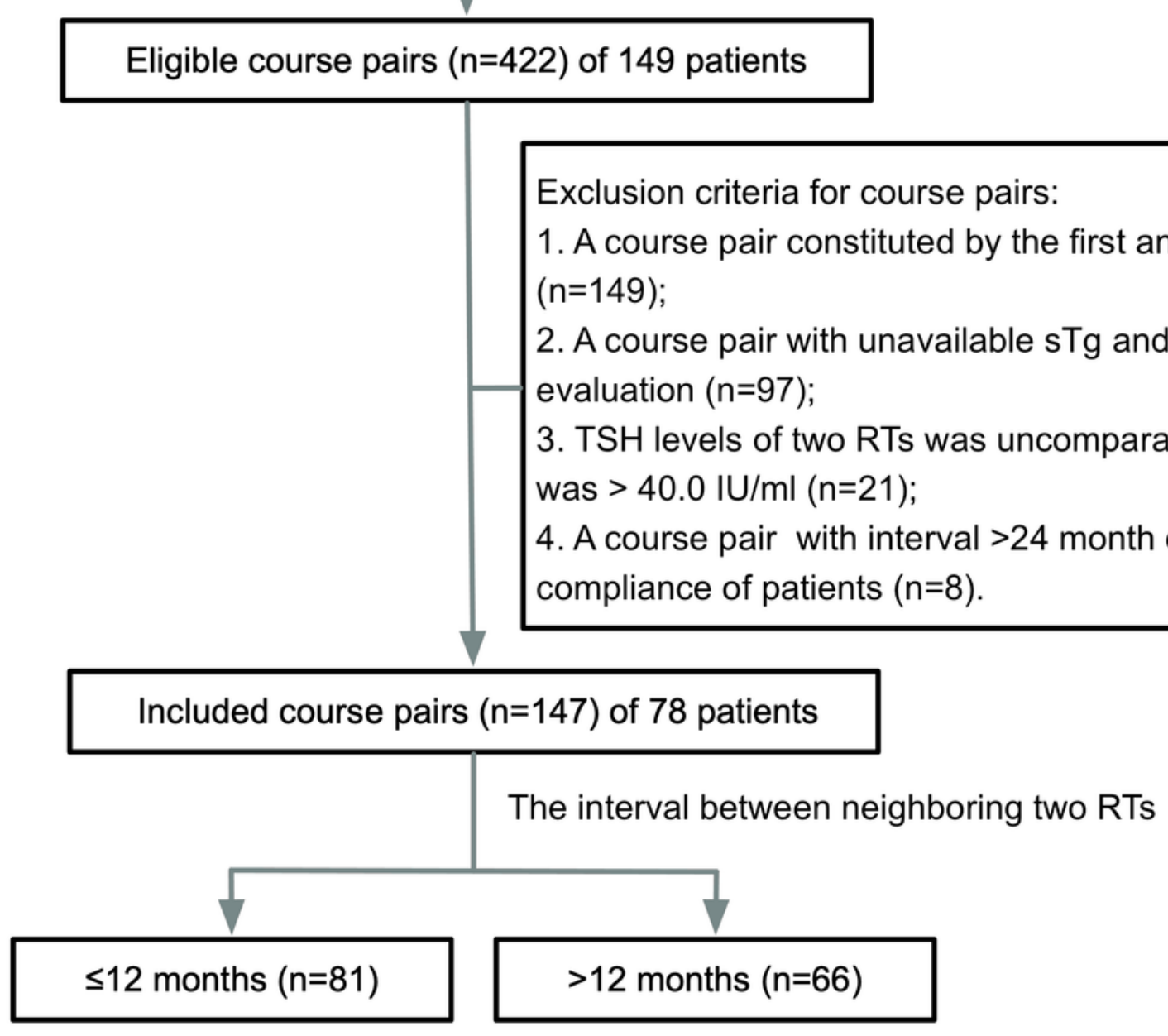

Figure 1

The flowchart of the inclusion and exclusion of patients and courses. 


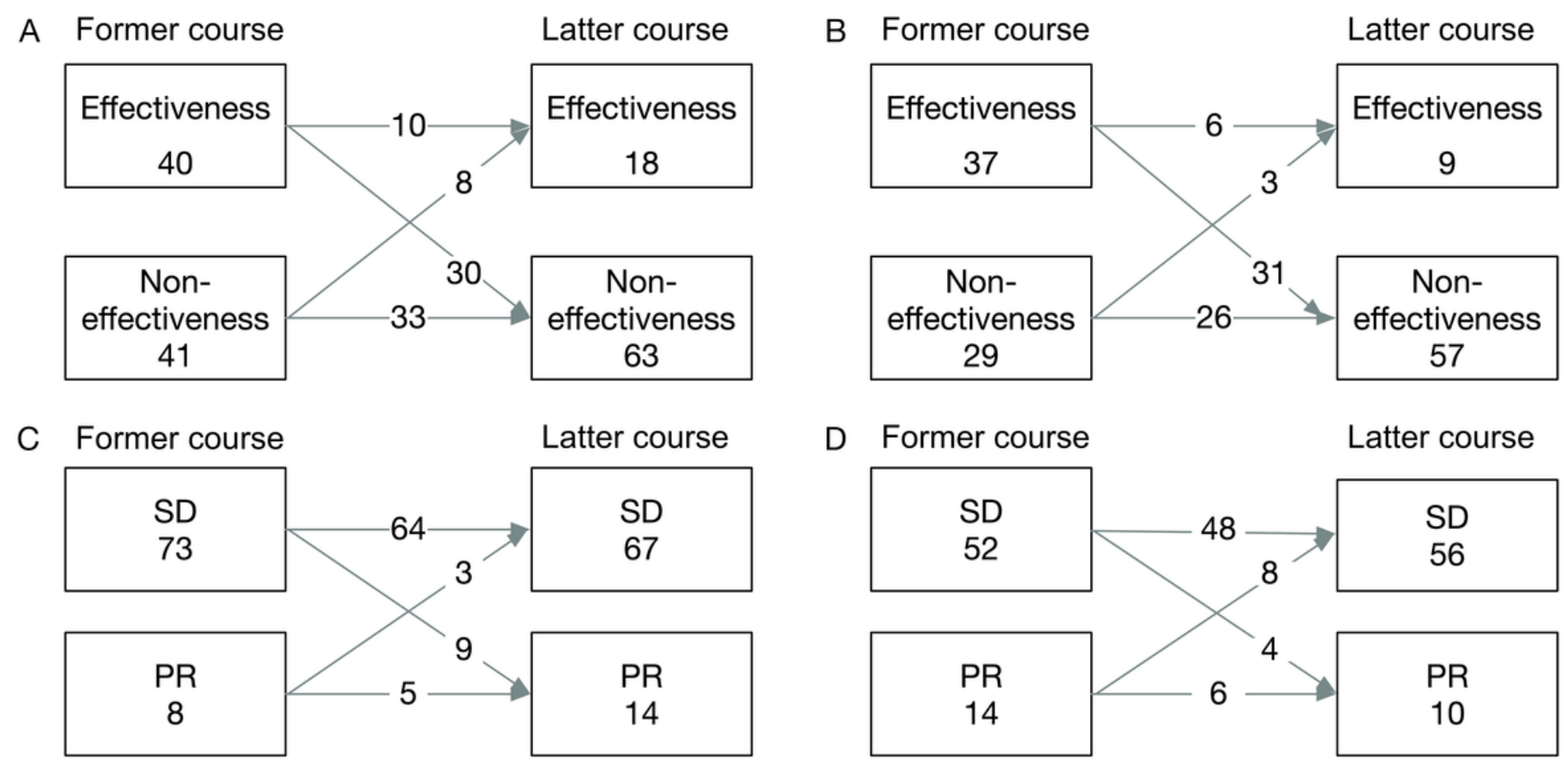

Figure 2

Flow of patients in course pairs according to biochemical response and structural response (A, C: interval $\leq 12 \mathrm{~m} ; \mathrm{B}, \mathrm{D}$ : interval >12 m). No difference was found in biochemical response between former and latter courses with regard to different intervals (Cochran-Mantel-Haenszel test, $P=0.325, P=0.456$ ). No difference was found in structural response between former and latter courses with regard to different intervals (Cochran-Mantel-Haenszel test, $\mathrm{P}=0.760, \mathrm{P}=0.563$ ).

a

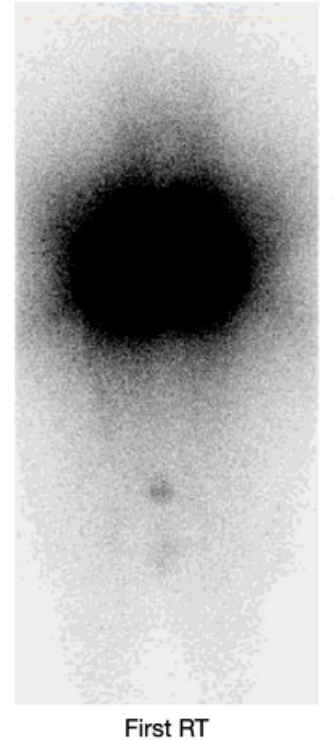

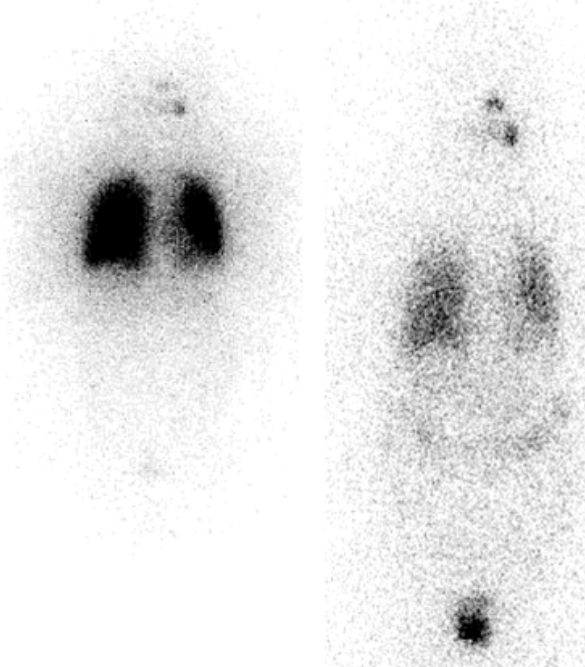

Second RT (Interval of 210d) Third RT (Interval of 273d)
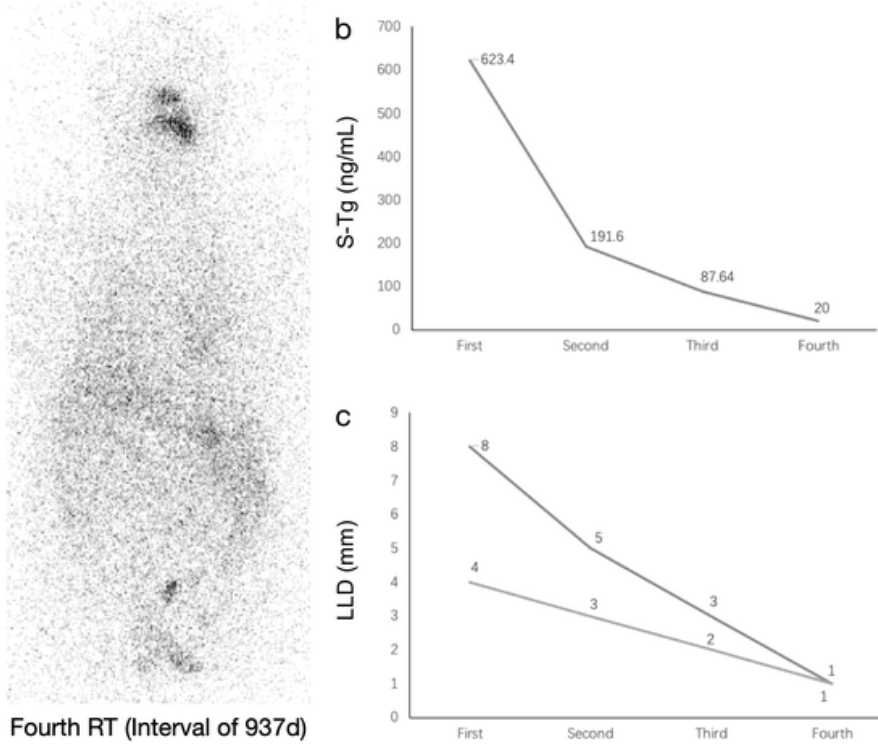

C

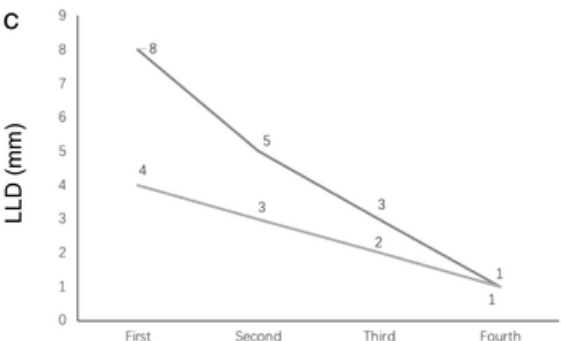

Figure 3 
A 65-year-old male papillary thyroid cancer patient (T4aN1bM1) was evaluated for biochemical effectiveness and structural PR in the third course of RT, indicating a remarkable response to repeated RTs. Then, we prolonged the interval of the fourth RT (937 days), and the $\Delta s T g \%$ and $\Delta$ LLD\% just before the fourth RT were $-77.2 \%$ and $-58.5 \%(b, c)$, respectively. Local radioactivity was noted in the lungs on a posttherapeutic whole body scan (R-WBS) (a). At the last follow-up (2 months after the fourth RT), the TSH-suppressed Tg showed a continuous decline.

\section{Supplementary Files}

This is a list of supplementary files associated with this preprint. Click to download.

- WangSupplementalData.docx 